\title{
Os "remédios do mato" por especialistas locais da comunidade São João da Várzea, Mossoró, RN, Brasil
}

\author{
The "remédios do mato" for specialists local community São João da Várzea, \\ Mossoró, RN, Brasil \\ Les spécialistes de la médecine «brousse» communauté locale São João da Varzea, \\ Mossoró, RN, Brasil
}

Los «arbusto medicina» especialistas comunidad de São João da Varzea, Mossoró, RN, Brasil

\author{
Ana Valéria Lacerda Freitas* \\ (anavalerialf@yahoo.com.br) \\ Maria de Fatima Barbosa Coelho** \\ (coelhomfstrela@gmail.com)
}

Recebido em 17/08/2013; revisado e aprovado em 10/09/2013; aceito em 16/02/2014

\begin{abstract}
Resumo: O objetivo neste estudo foi interpretar o conhecimento local de duas especialistas sobre os recursos vegetais terapêuticos. Adotaram-se as técnicas de pesquisa participativa, entrevistas semiestruturadas, história de vida, listagem livre e turnês guiadas. Foram identificadas 41 espécies, distribuídas em 28 famílias botânicas. Os aspectos fenológicos e de conservação das espécies observadas contribuem para o desenvolvimento de alternativas mais sustentáveis de uso e manejo dos recursos locais.

Palavras-chave: Plantas medicinais. Conhecimento local. Conservação de espécies.

Abstract: The objective of this study was to interpret the local knowledge of two experts on the therapeutic plant resources. Adopted the techniques of participatory research, semi-structured interviews, history of life, free listing and "walk-in-the-woods". We identified 41 species in 28 botanical families. The phenology and conservation of species observed contribute to the development of alternative, more sustainable use and management of local resources. Key words: Medicinal plants. Local knowledge. Plant conservation.

Résumé: L'objectif de cette étude était d'interpréter les connaissances locales des deux experts sur les ressources végétales thérapeutiques. Adopté les techniques de recherche participative, des entretiens semi-structurés, l'histoire de la vie, visite guidée et libre de liste. Nous avons identifié 41 espèces dans 28 familles botaniques. Le phénologique et la conservation des espèces observées contribuer à l'élaboration d'une utilisation plus durable de remplacement et la gestion des ressources locales.

Mots-clés: Les plantes médicinales. Les connaissances locales. La conservation des espèces.

Resumen: El objetivo de este estudio fue interpretar el conocimiento local de los dos expertos en los recursos terapéuticos de las plantas. Adoptó la tecnología de la investigación participativa, entrevistas semi-estructuradas, la historia de la vida, el listado libre y "walk-in-the-bosque." Se identificaron 41 especies de 28 familias botánicas. El fenológico y la conservación de las especies observadas contribuyen al desarrollo de usos alternativos, más sostenibles y la gestión de los recursos locales.

Palabras clave: Plantas medicinales. El conocimiento local. La conservación de las especies.
\end{abstract}

\section{Introdução}

A utilização de plantas para tratamento, cura e prevenção de doenças é uma das mais antigas formas de prática medicinal da humanidade (PASA, 2011). Esse uso, muitas vezes, se constitui como o único recurso disponível para o tratamento de doenças nas comunidades rurais, sobretudo em países em desenvolvimento (GUERRA et al., 2010; ROQUE et al., 2010; CUNHA; BORTOLOTTO, 2011; RICARDO, 2011), principalmente na região Nordeste, na qual $90 \%$ da população economicamente carente recorre às plantas medicinais para a cura de seus problemas de saúde (MATOS, 2002).

O conhecimento que as comunidades tradicionais possuem sobre os recursos vegetais foi por muito tempo subestimado pelos cientistas, que negligenciavam outras formas ou sistemas de conhecimento (ALBUQUERQUE, 2005). Para Maciel et al. (2002), as observações populares sobre o uso e a eficácia de plantas medicinais contribuem de forma relevante para a divulgação das virtudes terapêuticas dos vegetais, auxiliando

\footnotetext{
* Universidade Federal Rural do Semi Árido, Mossoró, RN, Brasil.

** Universidade da Integração Internacional da Lusofonia Afro Brasileira, Redenção, CE, Brasil.
} 
os pesquisadores na seleção de espécies para estudos botânicos, farmacológicos e fitoquímicos. Dessa forma, a informação coletada junto à população a respeito do uso de plantas é de fundamental importância (PASA, 2011), podendo contribuir para a construção do conhecimento científico.

Além disso, o resgate do conhecimento tradicional tem merecido atenção especial nos últimos anos devido à aceleração no processo de aculturação e à erosão genética provocada pela forte pressão antrópica e uso insustentável dos recursos naturais. A esmagadora cultura global, o capitalismo, aos poucos, tende a dissipar essa riqueza que o homem construiu de modo tão simbiótico com o meio ambiente que está ao seu redor (PASA; ÁVILA, 2010). Para Pilla et al. (2006), à medida que a relação com a terra passa por uma modernização e o contato com centros urbanos se intensifica, a rede de transmissão do conhecimento sobre plantas medicinais pode sofrer alterações, sendo necessário com urgência fazer o resgate deste conhecimento e das técnicas terapêuticas, como uma maneira de deixar registrado esse modo de aprendizado informal.

Por meio de estudos etnobotânicos, as plantas medicinais podem ter suas ações terapêuticas conhecidas para serem posteriormente comprovadas (OLIVEIRA; MENINI NETO, 2012), permitindo o entendimento das bases racionais para o uso medicinal de algumas espécies vegetais, desenvolvimento de fitoterápicos a baixo custo e a descoberta de novas drogas (SIVIERO et al., 2012). Essas pesquisas também podem auxiliar na identificação de práticas adequadas ao manejo da vegetação, já que, conforme Albuquerque (2005), o conhecimento das culturas locais fornece fortes elementos para a conservação dos recursos biológicos.

Estudos dessa natureza são ainda mais importantes, nos quais esses recursos são constantemente ameaçados, principalmente pela ação antrópica, como é o caso da caatinga. A caatinga é um bioma exclusivamente brasileiro, caracterizada por possuir plantas adaptadas fisiologicamente às condições de deficiência hídrica (TROVÃO et al., 2004) e por abranger uma grande diversidade biológica, sendo registradas 681 espécies de angiospermas, distribuídas em 62 famílias botânicas (LISTA DE ESPÉCIES DA FLORA
DO BRASIL, 2013). A Caatinga contém uma grande variedade de tipos vegetacionais, com elevado número de espécies e também remanescentes de vegetação ainda bem preservada, que incluem um número expressivo de táxons raros e endêmicos (GIULIETTI et al., 2003).

A diversidade de plantas medicinais conhecida na Caatinga é elevada, e sua obtenção na própria comunidade sugere uma forte correlação entre uso e conhecimento tradicional dessas plantas (MARTINS, 2012). Apesar dessa riqueza vegetal e de conhecimentos, e do risco envolvido nas práticas extrativistas e agropastoris insustentáveis que vêm reduzindo drasticamente suas populações de espécies, poucos são os estudos relacionados ao conhecimento envolvendo o uso e o manejo de plantas medicinais nesse bioma. Esse fato é ainda mais agravado por se tratar de um ecossistema pouco valorizado, considerado durante muito tempo como pobre em biodiversidade (TROVÃO et al., 2004).

Com $95 \%$ de sua cobertura vegetal inserida neste bioma, o Rio Grande do Norte, também possui uma grande carência de estudos relacionados às plantas medicinais sob uma abordagem etnobotânica, embora, recentemente, alguns tenham sido desenvolvidos (GUERRA et al., 2007; TORRES et al., 2007; MOSCA; LOIOLA, 2009; GUERRA et al., 2010; LOIOLA et al., 2010; ROQUE et al., 2010; SILVA; FREIRE, 2010; FREITAS et al., 2011; MORAIS, 2011; PAULINO et al., 2011; FREITAS et al., 2012; PAULINO et al., 2012).

Dessa forma, torna-se essencial o desenvolvimento de estudos com enfoque etnobotânico sobre as plantas utilizadas para fins medicinais no município de Mossoró-RN. A realização desses estudos proporcionará a valorização, o resgate e a preservação do conhecimento que foi, ao longo do tempo, acumulado pelas gerações, sobre as formas de uso e manejo das plantas medicinais, podendo, também, subsidiar trabalhos sobre o uso sustentável da biodiversidade. Assim, o presente trabalho teve como objetivo resgatar os conhecimentos tradicionais a respeito do uso, manejo e conservação de plantas medicinais na comunidade São João da Várzea, Mossoró, RN. 


\section{1 Área de estudo e comunidade}

A área de estudo está localizada às margens da RN 117, no sentido Mossoró - Governador Dix Sept Rosado, nas coordenadas $5^{\circ} 18^{\prime} 19,5^{\prime \prime}$ Sul e $037^{\circ} 24^{\prime} 46,8^{\prime \prime}$ Oeste, altitude de $28 \mathrm{~m}$, distante $18 \mathrm{~km}$ da sede do município de Mossoró, estado do Rio Grande do Norte. Mossoró possui um clima do tipo muito quente e semiárido, com estação chuvosa atrasando-se para o outono; precipitação pluviométrica média anual de $695,8 \mathrm{~mm}$; o período chuvoso ocorre entre os meses de fevereiro a abril com temperaturas médias anuais variando de $27,4{ }^{\circ} \mathrm{C}$ acompanhada de uma umidade relativa média anual de $70 \%$ e 2.700 horas de insolação (IDEMA, [s.d.]).

De acordo com o Instituto de Assistência Técnica e Extensão Rural do Rio Grande do Norte (EMATER, 2012), a comunidade São João da Várzea está inserida no Polo Passagem do Rio, que é composto por cerca de 400 famílias distribuídas em 11 comunidades e dois Assentamentos do Programa Nacional de Crédito Fundiário (PNCF). A comunidade é composta por 53 famílias que têm como principais atividades econômicas o cultivo de milho (Zea mays L.) e feijão (Vigna unguiculata L. Walp.) em condições de sequeiro, a produção de hortaliças e forrageiras, a pecuária de pequeno porte, abrangendo bovinocultura leiteira e de corte, ovinocaprinocultura e criação de aves caipiras, o extrativismo de palha e cera de carnaubeira (Copernicia prunifera (Mill.) H. E. Moore), a extração de rocha calcária e empregos fixos e temporários em cerâmicas localizadas na própria comunidade ou em comunidades vizinhas.

\section{Metodologia}

Primeiramente, foi realizada uma visita à liderança da comunidade, por intermédio de técnicos da Unidade Local da EMATERRN. Essa liderança representou papel fundamental no desenvolvimento deste trabalho, fornecendo informações sobre a comunidade, ajudando na articulação e realização das oficinas e agindo como mediador nos primeiros contatos com os informantes.

Durante as visitas e entrevistas realizadas, foi possível identificar os informantes que possuíam uma maior afinidade e envolvimento com o uso de plantas medicinais. Nesse contexto, foram selecionadas duas informantes-chaves para colaborar mais ativamente na pesquisa. A concepção de informante-chave adotada nesse trabalho baseou-se na maior riqueza de informações sobre o uso e manejo de plantas medicinais, o que tende a refletir em um maior conhecimento a respeito desses recursos (AMOROZO; VIERTLER, 2010). Assim, para a seleção das informantes-chaves, foi utilizada a amostragem não probabilística, que consiste em escolher os elementos da população de forma intencional (ALBUQUERQUE et al., 2010a).

A pesquisa foi realizada nos meses de agosto e setembro de 2012, com abordagem qualitativa, relativa a um nível de realidade que não pode ser quantificado, correspondendo ao universo de significados, motivos, aspirações, crenças, valores e atitudes, representando um espaço mais profundo das relações, dos processos e dos fenômenos que não podem ser reduzidos à operacionalização de variáveis (MINAYO, 2003). Dessa forma, foram realizadas entrevistas informais e semiestruturadas, observação direta e participante, história de vida, lista livre e turnê guiada ou "walk-in-the-woods", de acordo com as metodologias propostas por Albuquerque et al. (2010b) e Amorozo e Viertler (2010).

As informações obtidas foram, com a devida autorização dos entrevistados, registradas com o auxílio de um gravador portátil (Mp4) e fotografadas com câmera digital. Além disso, foram utilizadas as técnicas de anotação simultânea da comunicação e uso de diário de campo para informações adicionais. Todas as informações foram anotadas conforme obtidas nos questionários e entrevistas, empregando-se as mesmas terminologias usadas pelos informantes.

A maioria das plantas medicinais citadas durante as entrevistas foram encontradas durante a turnê-guiada, sendo, nesses casos, detalhadamente fotografadas, para posterior confirmação da identificação botânica através de bibliografia especializada (LORENZI; MATOS, 2002; MAIA, 2004; LORENZI, 2006; LORENZI; SOUZA, 2008). Algumas espécies foram herborizadas de acordo com técnicas estabelecidas em coletas botânicas, para posterior identificação taxonômica por especialistas. $\mathrm{O}$ sistema de classificação de plantas utilizado foi 
o do Angiosperm Phylogeny Group, conhecido como APG II (APG, 2003). A nomenclatura das espécies e seus autores foram confirmados utilizando-se a base de dados Trópicos ${ }^{\circledR}$ do Missouri Botanical Garden (TRÓPICOS, s.d.).

\section{Resultados e discussão}

É marcante a constatação pelas informantes do desaparecimento de antigas áreas de coleta e de suas plantas. As informações referentes às espécies citadas como medicinais e encontradas nos ambientes percorridos durante as trilhas encontram-se na Tabela 1.

Aqui tinha muito era papaconha, morreu tudinho. É no chão, estiradinha, bem alvinha a raizinha dela. Tinha batata de purga também, agora era grandona ela, ela nasce nos cantos do mofumbo. Mas não tem não, numa seca dessa ninguém ver elas não, só ver no inverno. (M. M. C. P., 63 anos).

As 41 espécies identificadas estão distribuídas em 28 famílias botânicas, sendo observada uma maior diversidade de plantas medicinais citadas por Dona Maria, que respondeu por $60,5 \%$ e $64,0 \%$ das famílias e espécies encontradas, respectivamente. A família com maior número de espécie foi a Euphorbiaceae (5 spp.), representada por velame (Croton campestris A. St. Hil.), marmeleiro preto (Croton sonderianus Müll. Arg.), pinhão roxo (Jatropha gossypiifolia L.), pinhão (Jatropha mollissima (Pohl) Baill.) e carrapateira (Ricinus communis L.). O destaque dessa família deve-se, provavelmente, à grande resistência dessas espécies à deficiência hídrica, consequência da estiagem ocorrida no município e em toda região semiárida no ano de 2012, ano em que foi realizada a pesquisa de campo. Em um estudo etnobotânico da flora da caatinga realizado em dois municípios do estado de Alagoas, Almeida et al. (2005) constataram que a família Euphorbiaceae (18 spp.) foi a que contribuiu com o maior número de espécies. 
Mossoró, RN, Brasil

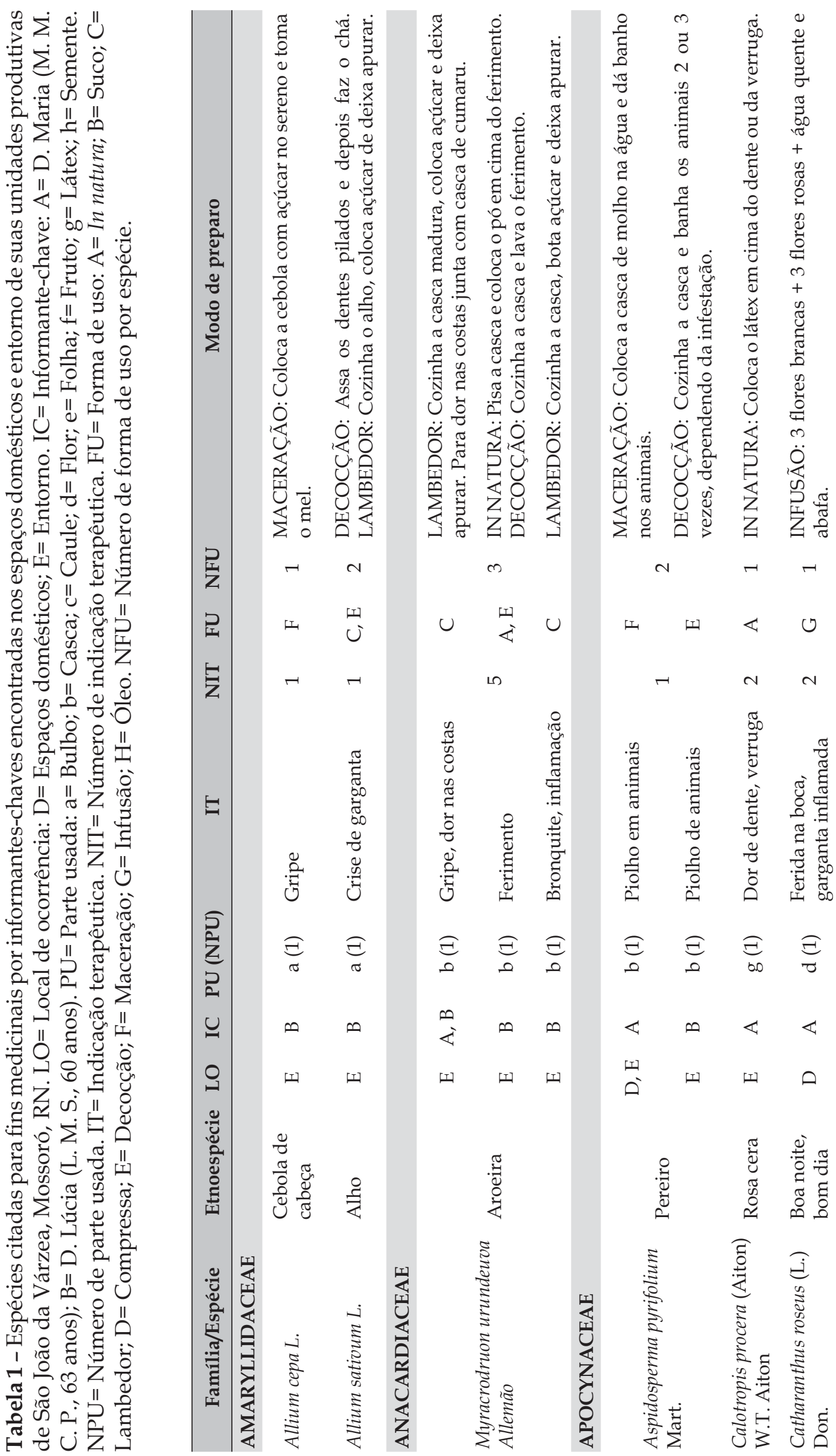




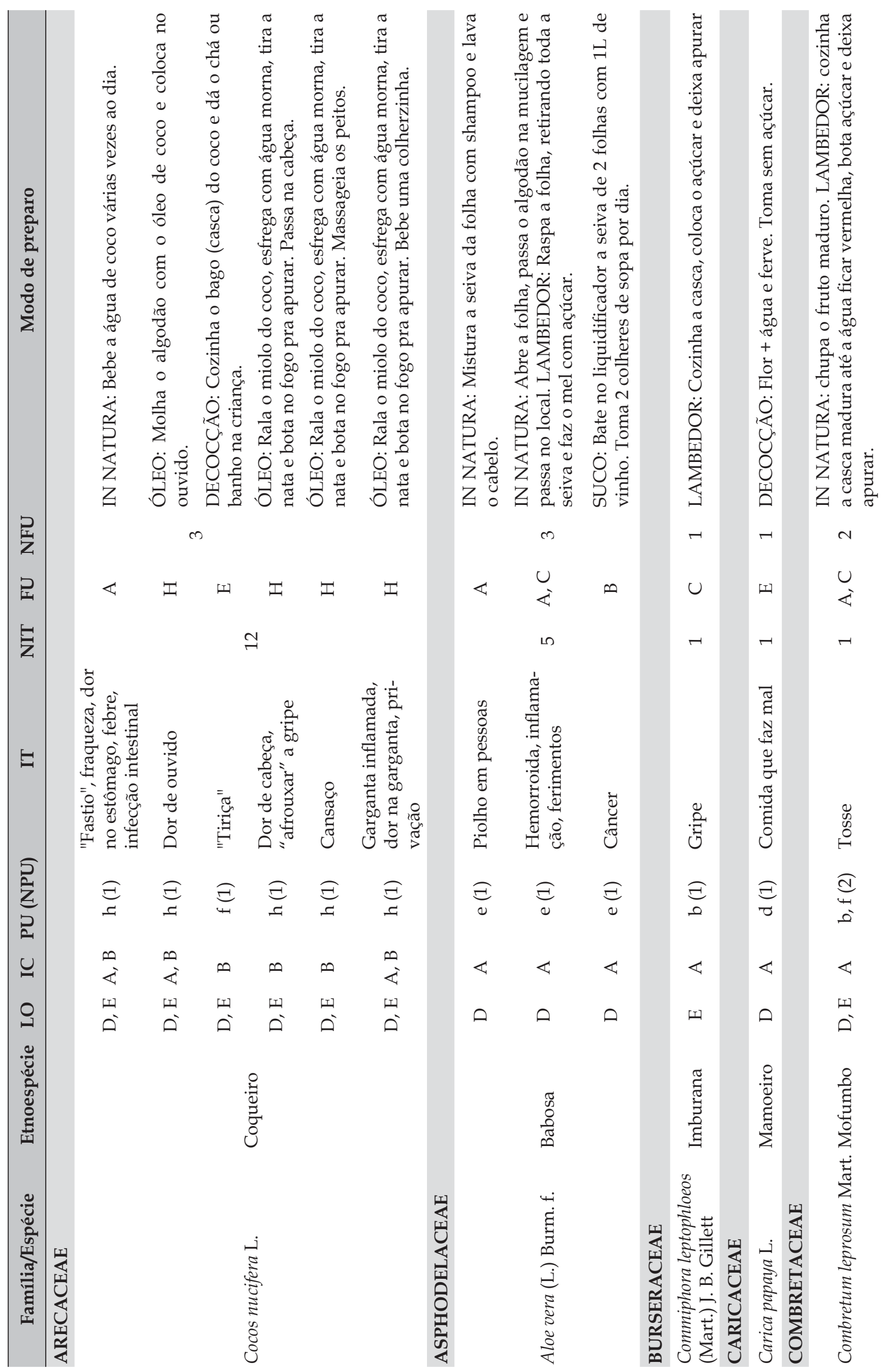


Mossoró, RN, Brasil

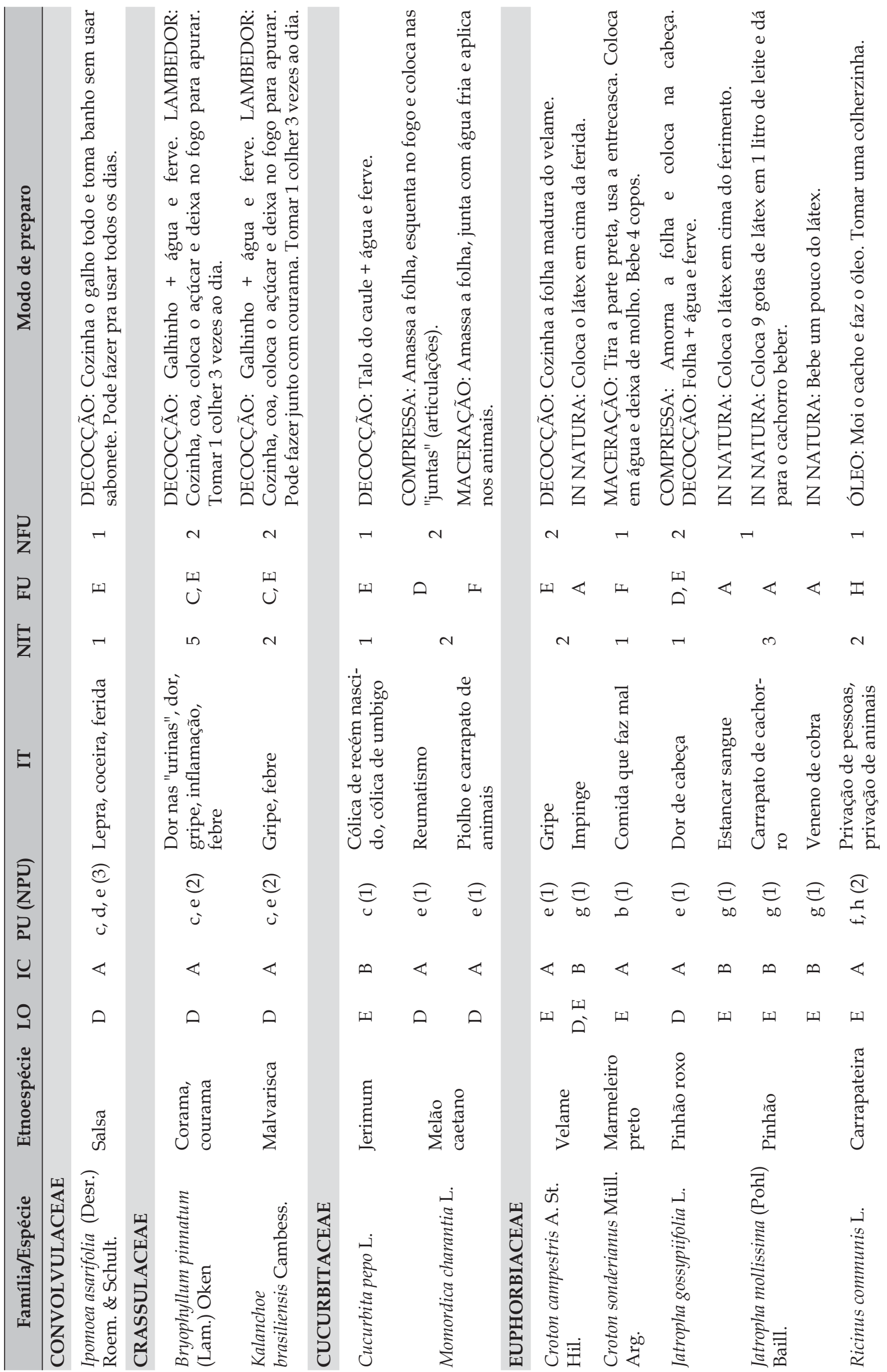




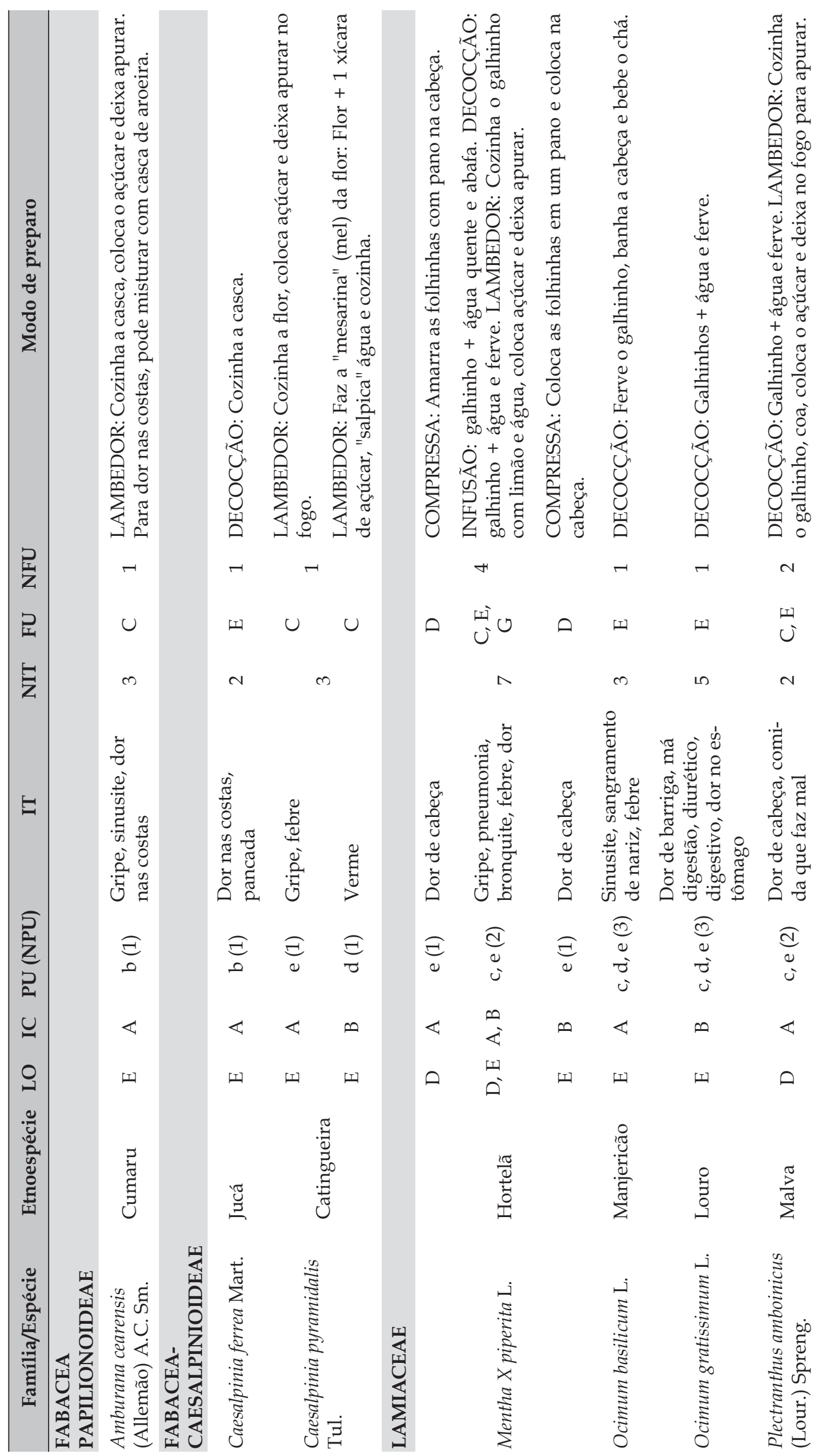


Mossoró, RN, Brasil

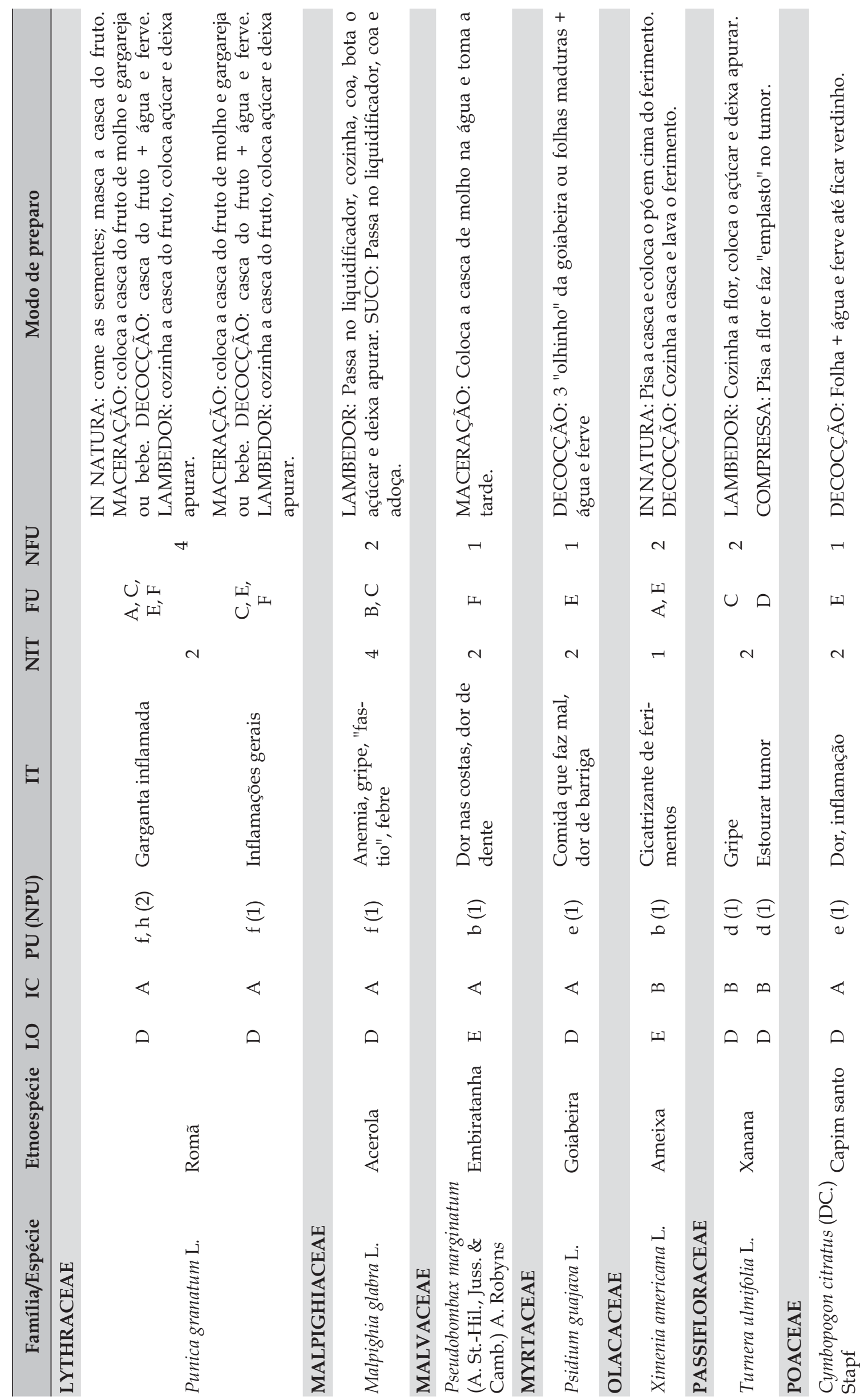




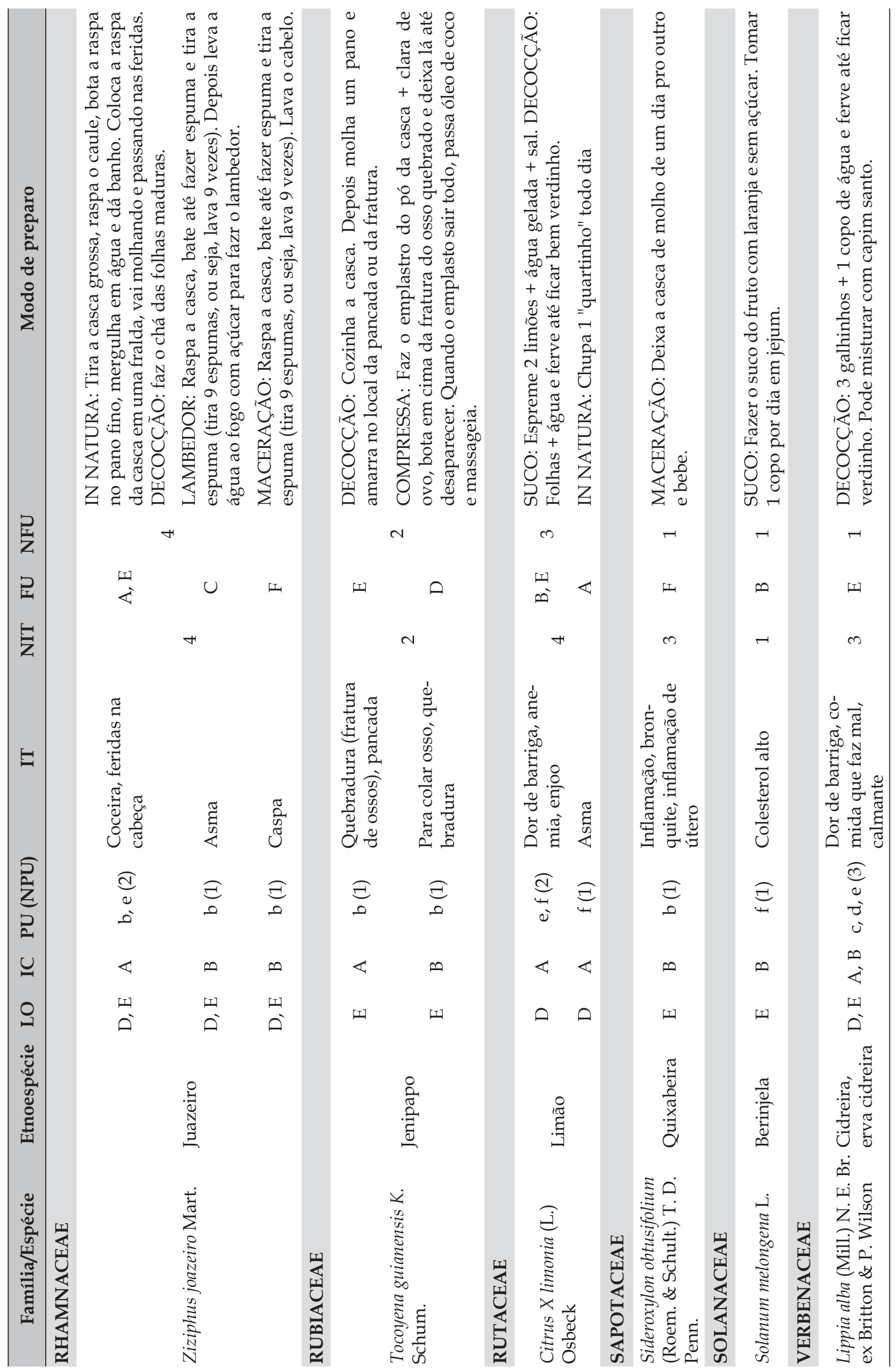


Outras famílias botânicas que se destacaram no estudo foram Lamiaceae (4 spp.), Apocynaceae (3 spp.), Amaryllidaceae (2 spp.), Crassulaceae (2 spp.) e Cucurbitaceae (2 spp.) . As demais famílias identificadas foram representadas por apenas uma espécie cada. De todas as espécies citadas, apenas 4 foram encontradas nas duas trilhas realizadas, são elas: aroeira (Myracrodruon urundeuva Allemão), coqueiro (Cocos nucifera L.), hortelã (Mentha X piperita L.) e cidreira ou erva cidreira (Lippia alba (Mill.) N. E. Br. ex Britton $\&$ P. Wilson).

Com a finalidade de orientar estudos e pesquisas que possam subsidiar a elaboração da lista de plantas medicinais e fitoterápicos a serem disponibilizados para uso da população, com segurança e eficácia para o tratamento de determinada doença, o Ministério da Saúde divulgou, em fevereiro de 2009, a Relação Nacional de Plantas Medicinais de Interesse ao SUS RENISUS (BRASIL, 2009). Nessa lista constam 71 plantas medicinais que apresentam potencial para gerar produtos de interesse ao Sistema Único de Saúde.

Das 41 espécies citadas e encontradas nos ambientes percorridos durante as trilhas, apenas $10(24,4 \%)$ encontram-se na RENISUS, são elas: Allium sativum L., Aloe vera (L.) Burm. f., Bryophyllum pinnatum (Lam.) Oken, Caesalpinia ferrea Mart., Jatropha gossypiifolia L., Mentha X piperita L., Momordica charantia L., Ocimum gratissimum L., Psidium guajava L. e Punica granatum L. Resultados semelhantes foram encontrados por Giraldi e Hanazaki (2010) que, estudando o uso e o conhecimento tradicional de plantas medicinais no Sertão do Ribeirão, em Florianópolis-SC, constataram $23(20 \%)$ espécies na RENISUS, do total de 114 citadas como medicinal. Estes resultados demonstram a importância de estudos etnobotânicos na divulgação de espécies utilizadas em diferentes regiões com potencial para serem incluídas na RENISUS.

A maioria das espécies encontradas $(73,2 \%)$ possui mais de uma indicação terapêutica, destacando-se o coqueiro (Cocos nucifera L.), que teve seu uso associado ao tratamento de 12 afecções, a saber: "fastio", fraqueza, dor no estômago, febre, infecção intestinal, dor de ouvido, "tiriça", dor de cabeça, garganta inflamada/dor na garganta, gripe, "cansaço" e privação. Para utilização como medicinal do coqueiro (Cocos nucifera L.), foram citadas três modos de preparo e uso, destacando-se o óleo e o consumo in natura (água de coco), com seis e cinco indicações terapêuticas, respectivamente. $\mathrm{O}$ uso através da decocção foi relatado por uma das informantes-chaveS para apenas uma indicação terapêutica, a "tiriça".

A água é soro, quando não tem o soro pra aplicar, a gente dá água de coco. A maior parte é pra febre, infecção intestinal, os médicos passam muito água de coco. [...] O óleo do coco é pra garganta, também pra untar o cabelo, assim, quando você tá com dor de cabeça, usa o óleo pra passar a dor de cabeça, pra cansaço também, a pessoa cansada gosta de passar, assim, nos peitos, passa na cabeça também pra 'afrochar' a gripe, quando a pessoa tá com a gripe muito forte. [...] Até pra dor de ouvido, usa também. Molha numa 'lanzinha' de algodão, ele morno e bota no ouvido. [...] Até a casca dele é pra 'tiriça', você faz o banho pra banhar a criança que tem 'tiriça' e é em primeiro lugar. [...] Pega, cozinha o bago do coco, dá o banho, e também, se você quiser, pega aquele chá, coloca na geladeira e fica dando pro bebê. Não tem 'tiriça' que se aguente, vai embora mesmo. (L. M. S, 60 anos).

O coco é o óleo, serve pra dor na garganta, pra dor de ouvido, você molha o algodão e coloca no ouvido. Quem é privado bebe, assim, um pouquinho. [...] A água de coco de soro pra quem tá com fastio, fraqueza, serve também pra dor no estômago. (M. M. C. P., 63 anos).

As informantes-chaves citaram um total de 53 indicações terapêuticas. Destas, uma se referiu ao tratamento de doença em animais domésticos e quatro às alternativas de controle de ectoparasitas, tanto em humanos como em animais domésticos. $\mathrm{O}$ maior número de espécies medicinais foi indicado para o tratamento de gripe (12 spp.), dor de barriga (diarreia) (9 spp.), má digestão, "comida que faz mal", digestivo (7 spp.), febre (7 spp.) e inflamações gerais, inflamação (6 spp.).

Mosca e Loiola (2009), em estudo sobre o uso popular de plantas medicinais no Rio Grande do Norte verificaram que várias espécies de plantas foram citadas para os mesmos grupos de doenças por sistemas corporais, sendo que o tratamento de gripe/garganta/ ouvido foi o mais citado. Medeiros et al. (2004) também encontraram o maior número de 
espécies para o tratamento da gripe, entre os moradores entrevistados em Mangaratiba-RJ.

Ao longo das entrevistas, pôde-se observar a utilização de termos populares e regionalizados para designar as doenças citadas pelas duas informantes-chaves. $\mathrm{O}$ uso dessas denominações sugere a existência de uma classificação desenvolvida por cada uma a partir de conhecimentos próprios e da comunidade em geral acumulados ao longo do tempo. Algumas dessas doenças foram citadas e descritas, mesmo não se tendo indicado uso de plantas para o tratamento de algumas delas. As principais foram: "mau olhado", "tiriça", "posta", "trombose, ramo ou AVC", "íngua ou landra" e "cobreiro".

$\mathrm{O}$ "mau olhado", diz que é o sangue da pessoa. [...] Não é de maldade não, é o sangue da pessoa mesmo que olha e aquela árvore morre, o menino fica doente. [...] A 'tiriça' é aquela que o menino fica todo amarelinho. [...] Posta é quando você leva uma pancada, aí o sangue fica coalhado. [...] Cobreiro é uma doença que dá, ela começa toda vermelha, que não pode encostar, dá até na criança. [...] Diz que se encostar uma ponta na outra a pessoa morre. Diz que pega de bicho que ferroa, mas não é não, é do sangue mesmo. [...] Íngua dá quando você pega uma ferida, aí tá muito inflamada aí forma. Vem de inflamação, de toda inflamação que você tiver. [...] Chama landra também. (M. M. C. P., 63 anos).

A influência da medicina ocidental no sistema terapêutico desenvolvido e utilizado por Dona Lúcia foi observada através da introdução de novas doenças, como o colesterol, que passou a fazer parte de sua rotina recentemente.

Antigamente a trombose era chamado de ramo, mas os médicos mudaram e agora não é mais nem trombose, já é outro nome, é AVC. (M. M. C. P., 63 anos).

Antigamente o AVC de hoje, que é a trombose, que já foi rama, e daí vai mudando os nomes, né? Aí meu avô conseguia curar o povo sabe com quê? Com gergelim e hortelã. (L. M. S., 60 anos).

Antigamente as pessoas fortes, gordas, não existia problema, n'era? Mas agora é engraçado, agora a pessoa não pode mais ficar forte, porque invés de ser uma pessoa forte, aí é a mais fraca do mundo, porque tem só musculatura, por dentro o colesterol "véi" sobe, né? (L. M. S., 60 anos).
Durante a entrevista foram citados diferentes formas de uso e preparo das plantas medicinais, sendo agrupadas em oito categorias definidas neste trabalho da seguinte maneira: consumo in natura, refere-se à utilização das partes das plantas que não passaram por processo de preparo ou manipulação; suco, obtido a partir de partes vegetais, principalmente frutos, espremidos ou triturados em liquidificador com água ou vinho e, em seguida, coados; compressa, consiste em colocar folhas, flores frescas e pó da casca, geralmente quentes, em contato direto com o local afetado, normalmente com auxílio de pedaços de tecido de algodão; óleo, obtido através de sementes espremidas, podendo-se utilizar o fogo no processo; infusão, obtido juntando-se água fervente sobre pedaços pequenos das partes vegetais, especialmente folhas, em um recipiente que permanece tampado por um período de 5 a 10 minutos, quando, então, é coado; decocção, obtido através do cozimento das partes vegetais por um período de 5 a 10 minutos dependendo da parte da planta em recipiente tampado; maceração, consiste em colocar as partes vegetais amassadas ou picadas em um recipiente contendo água e/ ou açúcar por um período de repouso que depende da parte utilizada, podendo chegar a 24 horas; e lambedor, constitui a mistura de açúcar com chás, obtidos por infusão ou decocção, deixando-se no fogo ou no sereno até desmanchar o açúcar.

De um modo geral, a forma de uso que mais se destacou foi a decocção, sendo citada como único ou alternativo modo de preparo de 24 espécies medicinais. A decocção também foi citada como a forma de preparo mais utilizada em outros estudos etnobotânicos (SILVA; SABLAYROLLES, 2009; SIVIERO et al., 2012). Em vários momentos, as informantes citaram o uso de plantas associadas a outras, sobretudo quando usadas na forma de lambedor. O lambedor correspondeu a 21,7\% das citações, sendo indicado como formulação para 15 espécies medicinais. Esse aspecto demonstra o risco associado a quem ingere esses tipos de formulações, principalmente no tocante à interação química dos princípios ativos presentes nas diferentes plantas utilizadas.

A aroeira, a quixabeira, a papaconha, a catingueira, o jatobá, a malva e o hortelã pra 
o lambedor de bronquite, pra bronquite, esse lambedor. Mistura sete qualidade de planta, a pessoa faz. Meu avô fazia com sete qualidade de planta pra quem tinha bronquite, , não era asma, bronquite mesmo. (L. M. S., 60 anos).

Outro aspecto observado foi a utilização de um critério de exclusão de algumas plantas para determinadas formas de preparo. Nesse sentido, Dona Maria classificou algumas plantas como "amargas", não podendo estas ser utilizadas sob formulações que precisem ser ingeridas, como chás e lambedores.

Quando não amarga, não faz mal. O negócio que faz mal à pessoa é quando amarga. Qualquer coisinha que não amarga, não faz mal. [...] O pereiro, pra remédio, pra chá, pra gente não pode, só serve só pra banho de animal, se tiver piolho numa cabra, pode botar a casca do pereiro de molho que mata. (M. M. C. P., 63 anos).

Foram mencionadas 8 partes vegetais para uso medicinal, com destaque para as folhas que foram empregadas para 27,2\% das preparações caseiras registradas para um total de 17 espécies. A maioria dos autores que trabalham com a etnobotânica de plantas medicinais também destaca a folha como a parte vegetal mais utilizada nessas preparações (MOSCA; LOIOLA, 2009; SILVA; SABLAYROLLES, 2009; GUERRA et al., 2010; FREITAS et al., 2012; SIVIERO et al., 2012).

Essa significativa maioria do uso de folhas deve-se, provavelmente, à frequente utilização de plantas medicinais herbáceas cultivadas em espaços domésticos. Almeida et al. (2005) afirmam que o grande número de ervas nas floras medicinais pode ser explicado, dentre outros fatores, pela existência de uma relação entre o tempo de vida e o tipo de defesa da planta, baseada na constatação de que as plantas anuais apresentam maior toxicidade em relação às perenes, e essa toxicidade possui importância nas espécies empregadas como plantas medicinais. Um exemplo é a espécie anual Catharanthus roseus (L.) Don., citada neste trabalho como bom dia e boa noite, que, apesar de ser considerada planta daninha, produz vincristina e vimblastina, drogas usadas na quimioterapia para o tratamento de alguns tipos de câncer (STEPP; MOERMAN, 2001).

Segundo Castellucci et al. (2000), o amplo uso das folhas no preparo de remédios ca- seiros pode estar relacionado com a facilidade de colheita, uma vez que estão disponíveis na maior parte do ano. Outros estudos alegam que a maioria das espécies vegetais tende a concentrar os princípios ativos nas folhas, fornecendo indicativo importante na estratégia de defesa contra herbivoria (STEPP, 2004), o que corrobora a importância do uso dessas partes vegetais de plantas medicinais.

As cascas também tiveram grande expressão nos resultados encontrados, respondendo pela utilização em $22,2 \%$ das preparações de 12 espécies. Esses resultados podem ser justificados pela maior resistência de espécies arbustivas e arbóreas às condições climáticas predominantes na região semiári$\mathrm{da}$, aumentando, consequentemente, a disponibilidade das cascas. Oliveira et al. (2005), em estudo etnobotânico realizado em Riachão de Malhada de Pedra, município de Caruaru-PE, verificaram que para $76 \%$ das espécies a maior pressão é sobre as cascas do caule, largamente usadas por estarem disponíveis o ano todo. Sobre esse aspecto, Albuquerque e Andrade (2002) enfatizam que normalmente o caule ou sua casca é preferencialmente mais coletado para uso medicinal na caatinga, devido à continuada oferta temporal do recurso. De acordo com Ferraz et al. (2005), as árvores têm maior uso por se constituírem em recurso permanente, enquanto as espécies herbáceas estão ausentes na estação seca.

De árvore usa a casca, é a casca. É a casca da aroeira, a casca do cumaru, casca da imburana, tudo é pra fazer remédio. (M. M. C. P., 63 anos).

As partes das plantas a serem utilizadas só são coletadas no momento que se verifica a necessidade, não havendo armazenamento delas por nenhuma das informantes-chaves. No momento da coleta, alguns aspectos são considerados por Dona Maria, conforme relato abaixo.

A folha da goiaba serve se for a madura, que é pra dor de barriga, ou o 'olho', é três 'oinho'. O velame é pra chá também, é a folha madura. [...] As cascas, casca de aroeira, só serve madura, casca de mofumbo, a folha do velame, a folha da goiaba, tudo só serve madura ou os 'oinho'. O marmeleiro, tanto faz. (M. M. C. P., 63 anos).

Observou-se que as duas informantes possuem concepções diferentes quanto à 
dosagem indicada da planta ou do produto medicinal. Dona Maria considera importante o cuidado na administração da planta, utilizando o critério da idade da pessoa para definir a quantidade a ser ingerida. Enquanto isso, Dona Lúcia afirmou que não possui um critério estabelecido de dosagem que considere a idade ou o peso da pessoa na administração das plantas medicinais, sendo considerada apenas a necessidade e o desejo de cura, conforme constatado em seu relato de uso da quixabeira (Sideroxylon obtusifolium (Roem. \& Schult.) T. D. Penn.). Esse aspecto remete à concepção de que o uso de plantas medicinais não possui contraindicações, evidenciando os riscos de utilização indiscriminada dessas plantas.

Ninguém pode tomar nada exagerado, tudo tem o total. [...] Sendo criança é menos, sendo adulto aumenta a dose, porque também bem fraquinho não serve, né? (M. M. C. P., 63 anos).

A quixabeira é feita pra inflamação, mas principalmente para inflamação de útero. Quando tiver uma inflamação pode tomar a água dela que ela ajuda a desinflamar. [...] Toma um copo, toma xícara, toma colher, depende do organismo da pessoa, toma o tanto que quiser, não tem contraindicação, que tome uma 'medidinha' assim, uma colherzinha assim, não, você toma o tanto que quer. Meu avô dizia: 'você é quem sabe, se quiser ficar bom logo, tome muito remédio, vocês podem tomarem, agora se vocês não quiserem ficar bom logo, fiquem tomando de pingo em pingo', ele dizia. (L. M. S., 60 anos).

\section{Considerações finais}

A tradição e a sabedoria dos antepassados continuam regendo as práticas medicinais das informantes-chaves, mesmo sendo observada a influência da medicina ocidental no contexto de vida. Assim, o conhecimento sobre o uso das plantas medicinais, considerado por ambas como uma herança de seus avós, foi codificado através de experiências cotidianas e memorizado de acordo com convicções e necessidades próprias.

A realização deste estudo proporcionou o resgate, a valorização e a preservação do conhecimento tradicional e proporcionou a observação de aspectos fenológicos e de conservação das espécies medicinais. Assim, o estudo pode contribuir para o desenvolvimento de alternativas mais sustentáveis de manejo dos recursos e também como base para outros estudos etnodirigidos no bioma caatinga.

\section{Referências}

ALBUQUERQUE, U. P.; ANDRADE, L. H. C. Uso de recursos vegetais da caatinga: o caso do agreste do estado de Pernambuco (Nordeste do Brasil). Interciência, Caracas, Venezuela, v. 27, n. 7, p. 336-346, jul. 2002.

ALBUQUERQUE, U. P. Etnobiologia e biodiversidade. Recife: NUPPEA, 2005. 78 p.

ALBUQUERQUE, U. P.; LUCENA, R. F. P.; LINS NETO, E. M. F. Seleção dos participantes da pesquisa. In: ALBUQUERQUE, U. P.; LUCENA, R. F. P.; CUNHA, L. V. F. C. (Org.). Métodos e técnicas na pesquisa etnobiológica e etnoecológica. Recife, PE: NUPPEA, 2010a. p. 21-37.

ALBUQUERQUE, U. P.; LUCENA, R. F. P.; ALENCAR, N. L. Métodos e técnicas para coleta de dados etnobiológicos. In: ALBUQUERQUE, U. P.; LUCENA, R. F. P.; CUNHA, L. V. F. C. (Org.). Métodos e técnicas na pesquisa etnobiológica e etnoecológica. Recife, PE: NUPPEA, $2010 \mathrm{~b}$. p. 39-64.

ALMEIDA, C. F. C. B. R.; ALBUQUERQUE, U. P.; SILVA, T. C. L.; AMORIM, E. L. C.; MAIA, M. B. S. Como as pessoas selecionam plantas para o uso medicinal? Evidências da química e da ecologia. In: ALBUQUERQUE, U. P.; ALMEIDA, C. F. C. B. R.; MARINS, J. F. A. (Org.). Tópicos em conservação, etnobotânica e etnofarmacologia de plantas medicinais e mágicas. Recife: NUPEEA/ Sociedade Brasileira de Etnobilogia e Etnoecologia, 2005. p. 263-286.

AMOROZO, M. C. M.; VIERTLER, R. B. A abordagem qualitativa na coleta e análise de dados em etnobiologia e etnoecologia. In: ALBUQUERQUE, U. P.; LUCENA, R. F. P.; CUNHA, L. V. F. C. (Org.). Métodos e técnicas na pesquisa etnobiológica e e tnoecológica. Recife, PE: NUPPEA, 2010. p. 67-82.

ANGIOSPERM PHYLOGENY GROUP - APG. An update of the Angiosperm Phylogeny Group classification for the orders and families of flowering plants: APG II. Botanical Journal of the Linnean Society, Londres, v. 141, n. 1, p. 399-436, 2003.

BRASIL. Ministério da Saúde. Renisus. fev. 2009. Disponível em: <http:/ / portalsaude.saude.gov.br/images/ pdf/2014/maio/07/renisus.pdf $>$. Acesso em: $19 \mathrm{fev}$. 2013.

CASTELLUCCI, S. et al. Plantas medicinais relatadas pela comunidade residente na Estação Ecológica de Jataí, município de Luís Antonio - SP: uma abordagem etnobotânica. Revista Brasileira de Plantas Medicinais, Botucatu, SP, v. 3, n. 1, p. 51-60, 2000.

CUNHA, S. A.; BORTOLOTTO, I. M. Etnobotânica de Plantas Medicinais no Assentamento Monjolinho, município de Anastácio, Mato Grosso do Sul, Brasil. Acta Botanica Brasilica, Belo Horizonte, MG, v. 25, n. 3, p. 685-698, 2011. 
FERRAZ, J. S. F.; MEUNIER, I. M. J.; ALBUQUERQUE, U. P. Conhecimento sobre espécies lenhosas úteis da mata ciliar do Riacho do Navio, Floresta, Pernambuco. Zonas Áridas, Lima, Peru, n. 9, p. 27-39, 2005.

FREITAS, A. V. L.; COELHO, M. F. B.; MAIA, S. S. S.; AZEVEDO, R. A. B. A percepção dos quintais rurais por crianças de São Miguel, Rio Grande do Norte, Brasil. Revista Verde de Agroecologia e Desenvolvimento Sustentável, Mossoró, RN, v. 6, n. 2, p. 212-220, jul./set. 2011.

FREITAS, A. V. L.; COELHO, M. F. B.; MAIA, S. S. S.; AZEVEDO, R. A. B. Plantas medicinais: um estudo etnobotânico nos quintais do Sítio Cruz, São Miguel, Rio Grande do Norte, Brasil. Revista Brasileira de Biociências, Porto Alegre, v. 10, n. 1, p. 48-59, jan./mar. 2012.

GIRALDI, M.; HANAZAKI, N. Uso e conhecimento tradicional de plantas medicinais no Sertão do Ribeirão, Florianópolis, SC, Brasil. Acta bot. bras., Belo Horizonte, MG, 24(2): 395-406, abr./jun. 2010.

GIULIETTI, A. M. et al. Diagnóstico da vegetação nativa do bioma Caatinga. In: SILVA, J. M. C.; TABARELLI, M.; FONSECA, M. T.; LINS, L. V. (Org.). Biodiversidade da caatinga: áreas e ações prioritárias para a conservação. Brasília, DF: Ministério do Meio Ambiente, Universidade Federal de Pernambuco, 2003. 382 p.

GUERRA, A. M. N. M.; CUNHA NETO, J. R.; MARQUES, J. V. A. D.; PESSOA, M. F.; MARACAJÁ, P. B. Plantas medicinais e hortaliças usadas para cura de doenças em residências da cidade de Mossoró-RN. Revista Verde de Agroecologia e Desenvolvimento Sustentável, Mossoró, RN, v. 2, n. 1, p. 70-77, jan./jul. 2007.

GUERRA, A. M. N. M.; PESSOA, M. F.; SOUZA, C. S. M.; MARACAJÁ, P. B. Utilização de plantas medicinais pela comunidade rural Moacir Lucena, Apodi-RN. Bioscience Journal, Uberlândia, MG, v. 26, n. 3, p. 442-450, maio/jun. 2010.

INSTITUTO DE DESENVOLVIMENTO SUSTENTÁVEL E MEIO AMBIENTE DO RIO GRANDE DO NORTE (IDEMA). Per l do seu município, [s.d.]. Disponível em: $<$ http://www.idema.rn.gov.br/contentproducao/aplicacao/ idema/socio_economicos/enviados/per 1_municipio.asp $>$. Acesso em: $\overline{10}$ jan. 2012.

INSTITUTO DE ASSISTÊNCIA TÉCNICA E EXTENSÃO RURAL DO RIO GRANDE DO NORTE (EMATER). Diagnóstico das comunidades do Polo Passagem do Rio, Mossoró$R N$. Mossoró, RN: EMATER-RN, 2012. 54p.

LISTA DE ESPÉCIES DA FLORA DO BRASIL 2013. Disponível em: <http:// floradobrasil.jbrj.gov.br>. Acesso em: 12 fev. 2013.

LOIOLA, M. I. B.; PATERNO, G. B. C.; DINIZ, J. A.; CALADO, J. F.; OLIVEIRA, A. C. P. Leguminosas e seu potencial de uso em comunidades rurais de São Miguel do Gostoso - RN. Revista Caatinga, Mossoró, RN, v. 23, n. 3, p. 59-70, jul./set. 2010.

LORENZI, H. Manual de identificação e controle de plantas daninhas: plantio direto e convencional. 6. ed. Nova Odessa, SP: Instituto Plantarum, 2006. 339p.

LORENZI, H.; MATOS, F. J. A. Plantas medicinais no Brasil: nativas e exóticas. Nova Odessa, SP: Instituto Plantarum, 2002. 512 p.
LORENZI, H.; SOUZA, H. M. Plantas ornamentais no Brasil: arbustivas, herbáceas e trepadeiras. 4 ed. Nova Odessa, SP: Instituto Plantarum, 2008. 1088p.

MACIEL, M. A. M.; PINTO, A. C.; VEIGA JR., V. F. Plantas medicinais: a necessidade de estudos multidisciplinares. Química Nova, São Paulo, v. 25, n. 3, p. 429-438, maio 2002.

MAIA, G. N. Caatinga: arvores e arbustos e suas utilidades. São Paulo: D \& Z, 2004. 413p.

MARTINS, R. C. V. Coleta e identificação de espécimes botânicos. Belém: Embrapa, 2012. (Série Documentos, 143).

MATOS, F. J. A. Farmácias vivas: sistemas de utilização de plantas medicinais projetado para pequenas comunidades. 4. ed. Fortaleza: Editora UFC, 2002. 267p.

MEDEIROS, M. F. T.; FONSECA, V. S.; ANDREATA, R. H. P. Plantas medicinais e seus usos pelos sitiantes da Reserva Rio das Pedras, Mangaratiba, RJ, Brasil. Acta Botânica Brasílica, Belo Horizonte, MG, v. 18, n. 2, p. 391-399, 2004.

MINAYO, M. C. S. Ciência, técnica e arte: o desafio da pesquisa social. In: MINAYO, M. C. S. (Org.). Pesquisa social: teoria, método e criatividade. 22. ed. Petrópolis: Vozes, 2003. p. 9-29.

MORAIS, V. M. Etnobotânica nos quintais da comunidade de Abderramant em Caraúbas-RN. 2011. 112f. Tese (Doutorado em Fitotecnia: Área de concentração em Agricultura Tropical) - Programa de Pós-Graduação em Fitotecnia, Universidade Federal Rural do Semiárido, Mossoró, RN, 2011.

MOSCA, V. P.; LOIOLA, M. I. B. Uso popular de plantas medicinais no Rio Grande do Norte, nordeste do Brasil. Revista Caatinga, Mossoró, RN, v. 22, n. 4, p. 225-234, out./dez. 2009.

OLIVEIRA, E. R.; MENINI NETO, L. Levantamento etnobotânico de plantas medicinais utilizadas pelos moradores do povoado de Manejo, Lima Duarte MG. Rev. Bras. Pl. Med., Botucatu, SP, v. 14, n. 2, p. 311-320, 2012.

OLIVEIRA, R. L. C.; LINS NETO, E. M. F.; ALBUQUERQUE, U. P.; ARAUJO, E. L. Prioridades de conservação de plantas medicinais. In: ALBUQUERQUE, U. P.; ALMEIDA, C. F. C. B. R.; MARINS, J. F. A. (Org.). Tópicos em conservação, etnobotânica e etnofarmacologia de plantas medicinais e mágicas. Recife: NUPEEA/ Sociedade Brasileira de Etnobilogia e Etnoecologia, 2005. p. 165-188

PASA, M. C.; ÁVILA, G. Ribeirinhos e recursos vegetais: a etnobotânica em Rondonópolis, Mato Grosso, Brasil. Interações, Campo Grande, v. 11, n. 2 p. 195-204, jul./ dez. 2010.

PASA, M. C. Saber local e medicina popular: a etnobotânica em Cuiabá, Mato Grosso, Brasil. Boletim do Museu Paraense Emílio Goeldi, Belém, PA, v. 6, n. 1, p. 179-196, jan./abr. 2011.

PAULINO, R. C.; HENRIQUES, G. P. S. A.; COELHO, M. F. B.; ARAUJO, P. V. N. Riqueza e importância das plantas medicinais do Rio Grande do Norte. Revista de Biologia e Ciências da Terra, João Pessoa, PB, v. 11, n. 1, p. 157-168, 2011. 
PAULINO, R. C.; HENRIQUES, G. P. S. A.; MOURA, O. N. S.; COELHO, M. F. B.; AZEVEDO, R. A. B. Medicinal plants at the Sítio do Gois, Apodi, Rio Grande do Norte State, Brazil. Revista Brasileira de Farmacognosia, Curitiba, PR, v. 22, n. 1, p. 29-39, jan./fev. 2012.

PILLA, M. A. C.; AMOROZO, M. C. M.; FURLAN, A. Obtenção e uso das plantas medicinais no distrito de Martim Francisco, município de Mogi-Mirim, SP, Brasil. Acta Botanica Brasílica, Belo Horizonte, MG, v. 20, n. 4, p. 789-802, 2006.

RICARDO, L. G. P. S. Estudos etnobotânicos e prospecção fitoquímica das plantas medicinais utilizadas na comunidade Horto, Juazeiro do Norte-CE. 2011. 87 f. Dissertação (PósGraduação em Ciências Florestais - Ecologia e Manejo dos Recursos Florestais) - Centro de Saúde e Tecnologia Rural, Universidade Federal de Campina Grande (UFCG), Campina Grande, PB, 2011.

ROQUE, A. A.; ROCHA, R. M.; LOIOLA, M. I. B. Uso e diversidade de plantas medicinais da Caatinga na comunidade rural de Laginhas, município de Caicó, Rio Grande do Norte (Nordeste do Brasil). Revista Brasileira de Plantas Medicinais, Botucatu, SP, v. 12, n. 1, p. 31-42, jan./mar. 2010.

SILVA, E. R. R.; SABLAYROLLES, M. G. P. Quintais agroflorestais por colonos migrantes: as plantas medicinais em Vila Nova, Mojuí dos Campos (Santarém/ PA). CONGRESSO BRASILEIRO DESISTEMAS AGROFLORESTAIS, 7.: Diálogo e integração de saberes em sistemas agroflorestais para sociedades sustentáveis, 2009. Anais... Luziânia, 2009. p. 1-4.
SILVA, T. S.; FREIRE, E. M. X. Abordagem etnobotânica sobre plantas medicinais citadas por populações do entorno de uma unidade de conservação da caatinga do Rio Grande do Norte, Brasil. Revista Brasileira de Plantas Medicinais, Botucatu, SP, v. 12, n. 4, p. 427-435, out./dez. 2010.

SIVIERO, A.; DELUNARDO, T. A.; HAVERROTH, M.; OLIVEIRA, L. C.; MENDONÇA, A. M. S. Plantas medicinais em quintais urbanos de Rio Branco, Acre. Revista Brasileira de Plantas Medicinais, Botucatu, SP, v. 14, n. 4, p. 598-610, out./dez. 2012.

STEPP, J. R.; MOERMAN, D. E. The importance os weeds in ethnopharmacology. Journal of Ethnopharmacology, v. 75, n. 1, p. 19-23, apr. 2001.

STEPP, J. R. The role of weeds as sources of pharmaceuticals. Journal of Ethnopharmacology, v. 92, p. 163-166, 2004.

TORRES, D. F.; OLIVEIRA, E. S.; ALVES, R. R. N.; VASCONCELLOS, A. Levantamento etnoecológico da biodiversidade da península de Galinhos, Rio Grande do Norte. CONGRESSO DE ECOLOGIA DO BRASIL, 8. Anais... Caxambu, MG, 2007.

TROPICOS. Missouri Botanical Garden. [s.d.]. Disponível em: <http:/ / www.tropicos.org>. Acesso em: 8 jan. 2013.

TROVÃO, D. M. B. M.; SILVA; S. C.; SILVA, A. B.; VIEIRA JUNIOR, R. L. Estudo comparativo entre três fisionomias de Caatinga no estado da Paraíba e analise do uso das espécies vegetais pelo homem nas áreas de estudo. Revista de Biologia e Ciências da Terra, Macapá, AP, v. 4, n. 2, p. 1-5, 2o sem. 2004. 